\title{
CLINICAL PROBLEMS OF THYROTOXICOSIS
}

\author{
BY
}

PETER McEWAN, M.A., M.B., F.R.C.S.Ed.

Honorary Surgeon, Bradford Royal Infirmary

(With Special Plate)

Among the many interesting problems of thyrotoxicosis there is none more urgent and more obscure than the high and rapidly increasing death rate. During the year 1936 no fewer than 1,696 deaths were attributed to that condition in England and Wales. There has been a steady rise for many years, the exact figures being:

\begin{tabular}{|c|c|c|c|c|c|c|c|c|c|c|c|c|c|}
\hline Year & . & 1913 & 1914 & 1915 & 1916 & 1917 & $\mid 1918$ & 1919 & 1920 & 1921 & 1922 & $|1923|$ & 1924 \\
\hline $\begin{array}{l}\text { Males } \\
\text { Females . }\end{array}$ & $\because$ & $\begin{array}{r}42 \\
368\end{array}$ & $\begin{array}{r}38 \\
434\end{array}$ & $\begin{array}{r}32 \\
400 \\
\end{array}$ & $\begin{array}{r}47 \\
399 \\
\end{array}$ & $\begin{array}{r}40 \\
395 \\
\end{array}$ & \begin{tabular}{|r|}
466 \\
357
\end{tabular} & $\begin{array}{r}56 \\
473 \\
\end{array}$ & $\begin{array}{r}46 \\
464 \\
\end{array}$ & $\begin{array}{r}54 \\
533 \\
\end{array}$ & $\begin{array}{r}63 \\
590 \\
\end{array}$ & $\begin{array}{r}56 \\
569 \\
\end{array}$ & $\begin{array}{r}46 \\
574\end{array}$ \\
\hline Year & .. & 1925 & 1926 & 1927 & 1928 & 1929 & 1930 & 1931 & |1932 & 1933 & $|1934| 1$ & 1935 & 1936 \\
\hline $\begin{array}{l}\text { Males .. } \\
\text { Females }\end{array}$ & $\because$ & $\begin{array}{r}64 \\
630\end{array}$ & $\begin{array}{r}84 \\
743\end{array}$ & \begin{tabular}{|r|}
91 \\
852
\end{tabular} & \begin{tabular}{|l|}
119 \\
933
\end{tabular} & \begin{tabular}{|l|}
128 \\
936
\end{tabular} & $\begin{array}{r}112 \\
1114 \\
\mid\end{array}$ & $\begin{array}{r}138 \\
1162\end{array}$ & $\left|\begin{array}{r}165 \\
1239\end{array}\right|$ & 1268 & $\mid$\begin{tabular}{|r|}
181 \\
1315
\end{tabular} & $\left|\begin{array}{r}183 \\
1378\end{array}\right|$ & \\
\hline
\end{tabular}

It is a curious fact that during the last ten years the operation for the cure of thyrotoxicosis has attained its peak of excellence, and has been pronounced the safest operation in major surgery. No agreement has been reached as to how to explain this wide gap between the magnificent possibilities of major surgery on the one hand and the rapidly rising mortality on the other. The main purpose here is to examine and discuss this problem. The primary method of approach has been by an investigation of the deaths during 1936. Through the courtesy of the Registrar-General I was furnished with the particulars of each death in England and Wales during that year as regards sex, age, place of residence, place of death, and causes of death. A careful analysis of these returns has been made from various points of view. For convenience the tables will be given first. They will be used in the subsequent discussion and interpreted in the light of clinical experience ; and I ask for indulgence if I fail to avoid some of the many fallacies inherent in statistics and deductions therefrom.

TABLE I.-Geographical Distribution

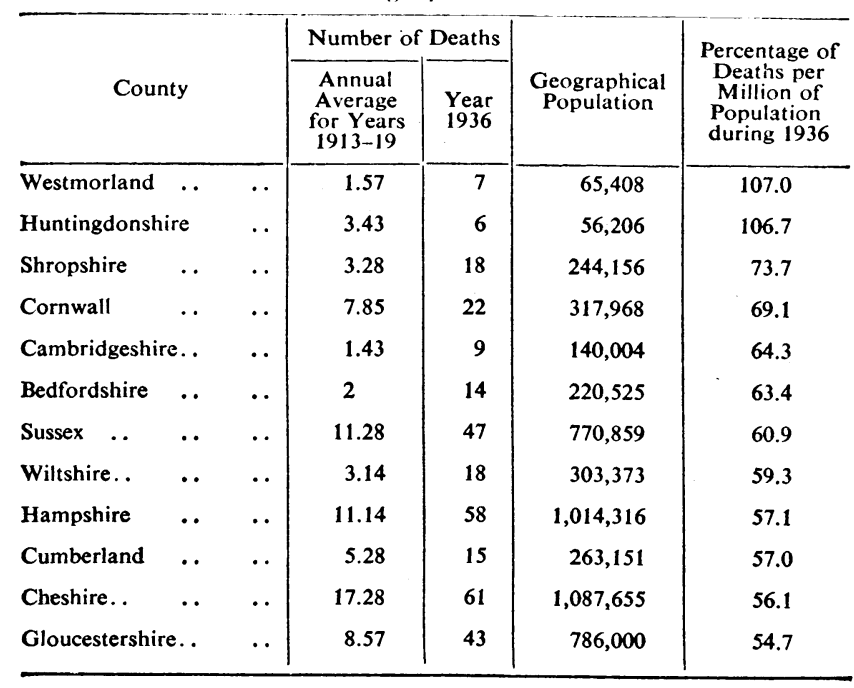

TABLE I.-Geographical Distribution (continued)

\begin{tabular}{|c|c|c|c|c|c|c|}
\hline & & & Number of & Deaths & & \\
\hline Count & & & $\begin{array}{c}\text { Annual } \\
\text { Average } \\
\text { for Years } \\
1913-19\end{array}$ & $\begin{array}{l}\text { Year } \\
1936\end{array}$ & $\begin{array}{l}\text { Geographical } \\
\text { Population } \\
.\end{array}$ & $\begin{array}{l}\text { Deaths per } \\
\text { Million of } \\
\text { Population } \\
\text { during } 1936\end{array}$ \\
\hline Somerset. . & .. & .. & 8.71 & 25 & 475,142 & 52.6 \\
\hline Hertfordshire & .. & .. & 2.71 & 21 & 401,206 & 52.3 \\
\hline Derbyshire & .. & .. & 8.71 & 38 & 757,374 & 50.1 \\
\hline Dorset .. & .. & .. & 2 & 12 & 239,352 & 50.1 \\
\hline Norfolk .. & .. & .. & 5.55 & 25 & 504,940 & 49.5 \\
\hline Northamptonsh & & .. & 3 & 15 & 309,474 & 48.4 \\
\hline Lancashire & .. & .. & 71.14 & 241 & $5,039,455$ & 47.8 \\
\hline Leicestershire & .. & .. & 4.85 & 25 & 541,861 & 46.1 \\
\hline Worcestershire & .. & .. & 4 & 19 & 420,056 & 45.2 \\
\hline Berkshire & .. & .. & 3.57 & 14 & 311,453 & 44.9 \\
\hline Lincolnshire & .. & .. & 8.43 & 28 & 624,589 & 44.8 \\
\hline Buckinghamshi & & .. & 2.57 & 12 & 271,586 & 44.2 \\
\hline Surrey ... & .. & .. & 9.85 & 53 & $1,180,878$ & 44.0 \\
\hline Yorkshire & .. & .. & 49.71 & 192 & $4,389,679$ & 43.7 \\
\hline Devonshire & .. & .. & 12.85 & 32 & 732,968 & 43.6 \\
\hline Kent $\quad .$. & .. & .. & 13.71 & 52 & $1,219,273$ & 42.6 \\
\hline Staffordshire & .. & .. & 13.57 & 58 & $1,431,359$ & 40.5 \\
\hline Nottinghamshir & & .. & 6.57 & 26 & 712,731 & 36.5 \\
\hline Herefordshire & .. & . & - & 4 & 111,767 & 35.7 \\
\hline Suffolk ... & .. & .. & 5.43 & 14 & 401,114 & 34.9 \\
\hline Warwickshire & .. & .. & 12.71 & 51 & $1,535,007$ & 33.2 \\
\hline Northumberlan & & .. & 8.85 & 22 & 756,782 & 29.0 \\
\hline Oxfordshire & .. & .. & 4.3 & 6 & 209,621 & 28.6 \\
\hline London and 1 & Middle & llesex & 48 & 155 & $6,035,731$ & 25.6 \\
\hline Essex $\quad .$. & .. & .. & 8.57 & 44 & $1,755,459$ & 25.1 \\
\hline Durham .. & .. & .. & 10.85 & 37 & $1,486,175$ & 24.9 \\
\hline Montgomery & .. & .. & 2.43 & 7 & 48,473 & 144.4 \\
\hline Merioneth & .. & .. & . & 5 & 43,201 & 115.7 \\
\hline Cardiganshire & $\cdots$ & .. & 285 & 7 & 55,184 & 126.8 \\
\hline Radnor .. & .. & .. & 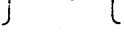 & - & & 一 \\
\hline Carnarvonshire & & .. & 3.14 & 12 & 120,829 & 99.3 \\
\hline Anglesey.. & .. & .. & ... & 3 & 49,029 & 61.1 \\
\hline Carmarthenshir & & .. & 4,43 & 13 & 179,100 & 72.5 \\
\hline Pembrokeshire & & .. & 1.70 & 1 & 87,206 & 11.4 \\
\hline $\begin{array}{l}\text { Brecknock (wi } \\
\text { fordshire) }\end{array}$ & ith $\mathbf{H e}$ & Here- & 3.71 & 4 & 57,775 & 69.2 \\
\hline Denbighshire & .. & .. & & 9 & 157,648 & 57.1 \\
\hline Flintshire & .. & .. & 1.0 & 4 & 112,889 & 35.4 \\
\hline Glamorganshire & & .. & 11.71 & 67 & $1,225,717$ & 54.6 \\
\hline Monmouthshire & & .. & 3 & 20 & 434,958 & 45.9 \\
\hline England and $\mathrm{V}$ & Wales & .. & 442.03 & $\begin{array}{r}1,691 \\
+5 \\
\end{array}$ & $39,696,662$ & 42.7 \\
\hline
\end{tabular}

${ }^{*}$ Residence not stated. 
TABLE II.-Sex and Age Incidence

\begin{tabular}{|c|c|c|c|c|c|c|c|c|}
\hline \multirow{2}{*}{\multicolumn{3}{|c|}{ Age }} & \multicolumn{3}{|c|}{ Non-operative Cases } & \multicolumn{3}{|c|}{ Operative Cases } \\
\hline & & & \multirow{2}{*}{$\frac{\text { Male }}{-}$} & \multirow{2}{*}{$\frac{\text { Female }}{-}$} & \multirow{2}{*}{$\frac{\text { Total }}{-}$} & \multirow{2}{*}{$\frac{\text { Male }}{-}$} & \multirow{2}{*}{$\frac{\text { Female }}{-}$} & \multirow{2}{*}{$\frac{\text { Total }}{-}$} \\
\hline $1-9$ & .. & .. & & & & & & \\
\hline $10-14$ & .. & .. & - & 3 & 3 & - & 1 & 1 \\
\hline $15-19$ & .. & .. & 2 & 11 & 13 & 3 & 8 & 11 \\
\hline $20-29$ & .. & .. & 13 & 36 & 49 & 4 & 37 & 41 \\
\hline 30-39 & .. & .. & 26 & 101 & 127 & 15 & 46 & 61 \\
\hline $40 \div 49$ & .. & .. & 28 & 230 & 258 & 9 & 63 & 72 \\
\hline 58-59 & .. & .. & 55 & 380 & 435 & 10 & 45 & 55 \\
\hline $6 \theta-69$ & .. & .. & 29 & 338 & 367 & 5 & 27 & 32 \\
\hline $70-79$ & .. & .. & 8 & 145 & 153 & - & 3 & 3 \\
\hline $80-89$ & .. & .. & 1 & 14 & 15 & - & - & - \\
\hline \multicolumn{2}{|c|}{ Totals } & .. & 162 & 1,258 & 1,420 & 46 & 230 & 276 \\
\hline
\end{tabular}

Total number of deaths, 1,696.

TABLE III.-Analysis of Non-operative Deaths

\begin{tabular}{|c|c|c|c|c|}
\hline & & Male & Female & Total \\
\hline (I) & 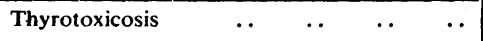 & 38 & 181 & 219 \\
\hline (11) & $\begin{array}{cccccc}\text { Thyrotoxicosis } & \text { plus } & \text { some } & \text { form } & \text { of heart } \\
\text { trouble } & . & \ldots & . . & . . & .\end{array}$ & 90 & 818 & 908 \\
\hline (III) & $\begin{array}{c}\text { Thyrotoxicosis ; } \\
\text { cations }\end{array}$ & 26 & 160 & 186 \\
\hline (IV) & (I) or (II) plus mental diseases & - & 16 & 16 \\
\hline (V) & Miscellaneous ... & 6 & 85 & 91 \\
\hline & Total & & & 1,420 \\
\hline
\end{tabular}

TABLE IV.-Analysis of Operative Deaths

\begin{tabular}{|c|c|c|c|c|c|c|c|c|}
\hline & & & & & & Male & Female & Total \\
\hline (I) & $\begin{array}{c}\text { Thyrotoxicosis } \\
\text { trouble }\end{array}$ & $\begin{array}{l}\text { some } \\
\ldots\end{array}$ & $\begin{array}{l}\text { form } \\
. .\end{array}$ & $\begin{array}{l}\text { of } \mathrm{h} \\
. .\end{array}$ & $\begin{array}{c}\text { heart } \\
. .\end{array}$ & 13 & 79 & 92 \\
\hline (II) & Thyrotoxicosis wit & ung con & nplicati & Ions & .. & 2 & 25 & 27 \\
\hline (III) & Anaesthetic death & .. & .. & .. & .. & 3 & 18 & 21 \\
\hline (IV) & Thyrotoxicosis plu & hock & .. & .. & .. & 2 & 17 & 19 \\
\hline (V) & Thyrotoxicosis ph & haemor & rhage & .. & .. & - & 3 & 3 \\
\hline (VI) & Miscellaneous .. & .. & .. & .. & .. & 26 & 88 & 114 \\
\hline & Total & .. & .. & .. & . & & & 276 \\
\hline
\end{tabular}

Table V.-Frequency of Mention of Certain Complications

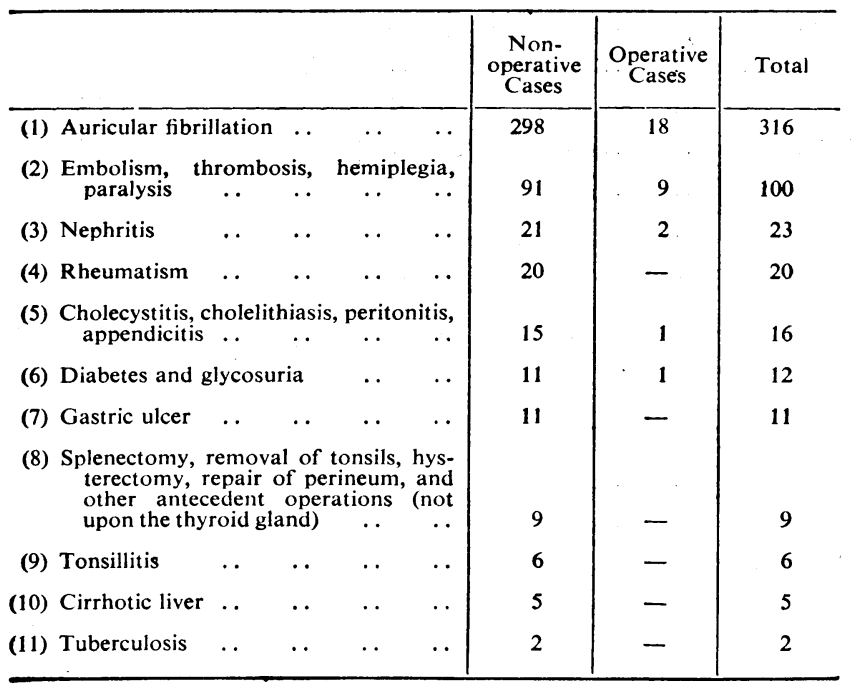

TABle VI.-Analysis of Cases of Embolism, Thrombosis, and Hemiplegia

\begin{tabular}{|c|c|c|c|c|c|c|c|c|}
\hline \multicolumn{4}{|c|}{ Medical } & \multicolumn{5}{|c|}{ Surgical } \\
\hline Cerebral embolism & \multirow{2}{*}{$\begin{array}{l}. . \\
. .\end{array}$} & \multirow{2}{*}{$\begin{array}{l}. . \\
. .\end{array}$} & \multirow{2}{*}{$\begin{array}{l}40 \\
23\end{array}$} & \multicolumn{3}{|c|}{ Pulmonary embolism } & \multirow{2}{*}{$\begin{array}{l}. . \\
. .\end{array}$} & \multirow{2}{*}{$\begin{array}{l}\cdots \\
. .\end{array}$} \\
\hline " thrombosis & & & & Cerebral & , & & & \\
\hline " haemorrhage & .. & .. & 1 & Femoral & " & & .. & .. \\
\hline Hemiplegia $\quad \ldots$ & .. & .. & 5 & Coronary & $"$ & & .. & .. \\
\hline Pulmonary embolism & .. & .. & 7 & Multiple emb & oli & •. & .. & .. \\
\hline Femoral & .. & .. & 2 & & & & & \\
\hline$"$ thrombosis & .. & .. & 2 & & & & & \\
\hline Cardiac embolism & .. & .. & 2 & & & & & \\
\hline Coronary thrombosis & .. & & 4 & & & & & \\
\hline Aortic embolism ... &.. & & 1 & & & & & \\
\hline Embolism of the iliac a & eries & & 1 & & & & & \\
\hline Subclavian embolism & .. & & 1 & & & & & \\
\hline Popliteal embolism & .. & & 1 & & & & & \\
\hline Thrombo-angiitis migr & &.. & 1 & & & & & \\
\hline Embolism (unspecified) & .. & . & 2 & & & & & \\
\hline
\end{tabular}

TABLE VII.-Analysis of Deaths under Anaesthetic

\begin{tabular}{llllll|llllll}
\hline Avertin &.. &.. &.. &.. & 1 & Gas and oxygen &.. &.. &.. & 2
\end{tabular}

\begin{tabular}{lll|l} 
Avertin, gas, and oxygen .. &.. & 5 & Paraldehyde, morphine, and percaine 1
\end{tabular}

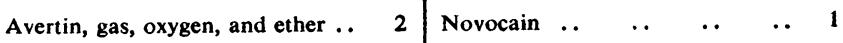

\begin{tabular}{llllll|llll} 
Ether &.. &.. &.. &. & 3 & Anaesthetic not specified &. & 2
\end{tabular}

Ether and oxygen .. $\quad . . \quad \ldots \quad$.. 1

Gas, oxygen, and ether $\quad . . \quad$.. 3

\section{Geographical Distribution}

A glance at the map (Fig. A) or a study of the figures given above will show the unevenness of the distribution, the highest percentage death rate occurring in Westmorland, the mountainous counties of Wales, and Huntingdon. A similar map was published by Campbell (1924-5) showing the geographical distribution of the death rate during the group of years 1913-19. The close parallelism of Campbell's map (Fig. B) and my own is remarkable. These two maps bring up two points of practical interest regarding thyrotoxicosis. First, the stress and strain of modern life has by some been regarded as an important factor in causation. Campbell's map does not bear this out, outlying mountainous counties not being the areas of greatest stress. Now if during the twenty years that intervene between the maps (the mortality rising from an average of 442 to 1,696 ) the stress of life were an important factor the distribution must have altered in favour of the big cities. It has not changed; therefore the stress and strain of life is, if a factor at all, a minor one, whereas the geographical factor is a major one, in causation. The second point is, Does the death incidence correspond to the incidence of simple goitre? Campbell studied this question carefully. He found that it was impossible to obtain reliable data as to the distribution of simple goitre; but he concluded that the evidence pointed to some degree of correspondence between the incidence of simple goitre and that of the thyrotoxic deaths. If this be true, and we take into account the acknowledged fact that many simple goitres become toxic, the further question arises, How far may the death rate be reduced by timely operation upon simple goitres or goitres that are in the early stages of toxicity? 


\section{Sex and Age Incidence}

The proportion of deaths, as regards sex, has scarcely altered: one man dies to seven or eight women; this fact scarcely supports the strain of life as a notable causal factor. Between the ages of 10 and 30 years 118 deaths occurred-sixty-five medical, fifty-three after operation: the number of surgical deaths at these ages appears unduly high. Many thyrotoxic patients live to a good old age (60 to 90 years). Have these old people become toxic shortly before death, or have they suffered for many years from ill-health and debility? Could operation have given them a longer and healthier life?

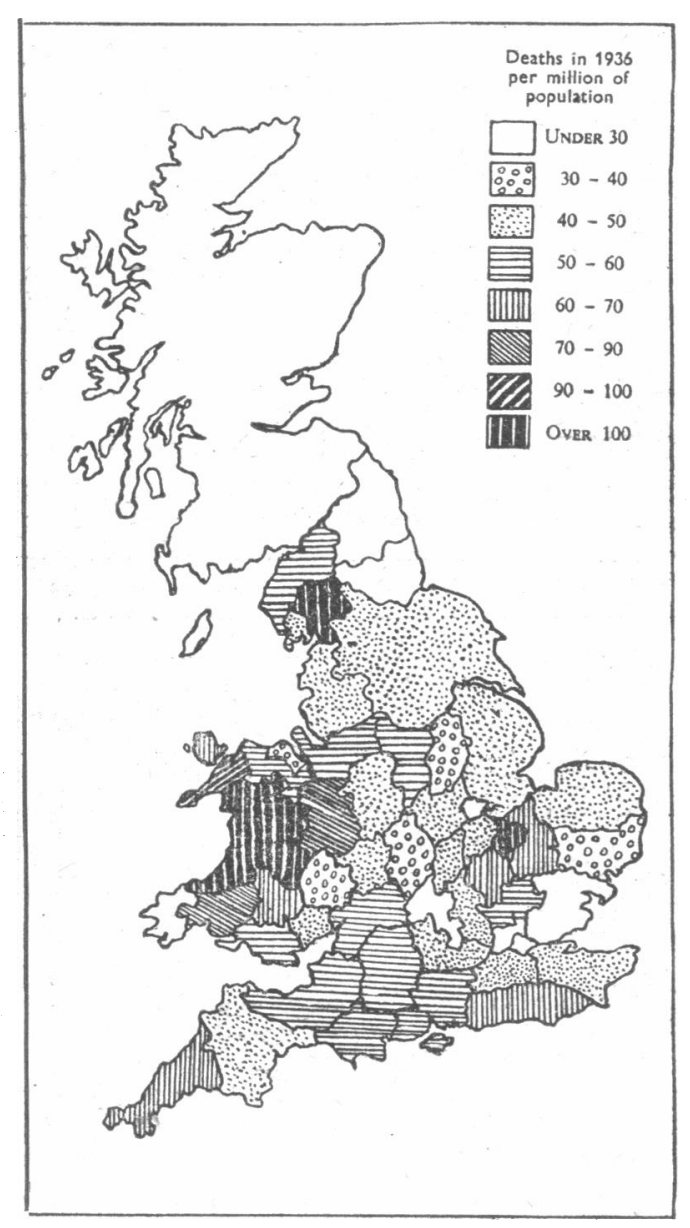

Fig. A. others not recorded) are numerous, and the deaths under anaesthesia (twenty-one) frequent. The varied nature of the anaesthetics used in these fatal cases suggests that skill in administration rather than the anaesthetics employed is the important factor in safety.

\section{The Medical Death Rate and Complications}

The mention of cardiac mischief in 908 cases, and of auricular fibrillation in 298 of these, shows how conspicuous a place cardiac complications take in the thyrotoxic picture. The vascular complications (embolism, thrombosis, hemiplegia) come next in frequency. It is noteworthy how often the brain is affected (sixty-nine
Fig. A.-Map of England and Wales, showing the distribution of deaths from thyrotoxicosis during 1936, according to the Registrar-General's Reports (based on place of residence, not place of death).

FIG. B.-Map of Great Britain and Ireland, showing the distribution of deaths from exophthalmic goitre during 1913-19, according to the Registrar-General's Reports (Campbell).

\section{The Surgical Deaths}

Operation is stated to be the cause of death in 276 cases. The number of deaths following operation may exceed this figure, as operation may not have been mentioned in certain cases, especially in the 219 cases in which thyrotoxicosis alone (or a synonym) is given as the cause of death. Indeed, de Courcy Wheeler (1934) states that, in those severe cases where ligation of arteries is performed, if the patient dies surgery is blameless: the operation therefore has no title to appear on the death certificate. The certifier may consider that death has occurred in spite of and not because of the operation. The figure of 276 appears high: the fatal chest complications (twenty-seven specified, and doubtless many cases); and that auricular fibrillation occurs thirty-eight times, whereas arteriosclerosis and hyperpiesia are mentioned only five times, suggesting that auricular fibrillation is a more notable factor in the production of thrombosis and embolism than high blood pressure. Nephritis is mentioned twenty-three times; rheumatism twenty times; the tonsil is not infrequently affected in rheumatism and also in thyrotoxicosis, and may form a connecting link. Diabetes and glycosuria occur less often (twelve times) than one would expect. Acute infections, especially pulmonary, but also tonsillitis and acute abdominal disease, are dangerous to the thyrotoxic patient ; so also, now and then, are operations on other organs. Tuberculosis is notably rare, being only twice mentioned, once as phthisis and once as an old-standing 
kyphosis: this is in line with the antagonism that is believed to exist between tuberculous disease and thyrotoxicosis.

\section{The Sphere of Iodine in Thyrotoxicosis}

The view is seriously advanced by Joll (1932) that the employment of iodine as a medical treatment is the new factor causing the increase in the death rate. It is weil recognized that the use of iodine in areas where goitre is endemic may lead to a definite increase in thyrotoxicosis; the increase in the deaths in the hilly districts, presumably endemic goitre areas, would support Joll's view. Many writers emphasize the danger of giving iodine to thyrotoxic patients, and uphold Joll in his contention that iodine should be entirely reserved for the use of the surgeon as a pre-operative safeguard. Fraser (1936), on the contrary, advocates that iodine be given a trial in all cases of thyrotoxicosis. Yet Fraser adds: "Iodine does not cure the condition, and it is doubtful if it cuts short the course of the disease." There is, however, no doubt at all that the case in which iodine has failed, sent later for operation, often causes the surgeon much anxiety, leading to increased hazard and delay. For, as Morley (1936) puts it, iodine acts best on virgin soil. Given for the first time it is a magnificent safeguard against post-operative toxic crises. Its full efficacy is seldom reached during a second or subsequent course. Whereas in acute primary thyrotoxicosis the pulse may often be controlled and kept at 80 during the first administration of iodine, the pulse in the same patient at a later date may race along at 130 to 140 despite the use of that substance, the originally soft and responsive gland being now large, firm, and indifferent. Iodine is to the thyrotoxic patient what opium is to the "acute abdomen": it masks the symptoms without curing the disease. Doubtless cases recover under iodine and under opium, but for the many failures the penalty is severe. Even in the very acute thyrotoxic crises where iodine must be used as an emergency measure to save life the surgeon should be called in, as these cases may speedily become operable, and the opportune time, if not taken advantage of, may not quickly recur. Unless surgical treatment is permanently excluded in an individual case iodine is best reserved for the use of the surgeon before operation. If iodine as a mode of treatment in general practice were given up it is quite possible that a fall would occur in the death rate.

The dose usually recommended for pre-operative treatment is from 5 to 15 minims of Lugol's solution three times a day for five to fourteen days before operation. The following two cases are of interest as showing that in rare cases this dose may be greatly exceeded with usefulness and safety.

\section{CASE 1}

Mrs. B., aged 28 (acute primary thyrotoxicosis, operated on during a severe crisis).-The patient had enjoyed good health until she suffered from crippling rheumatic arthritis (1929-30). This was cured by six to twelve months' treatment with thyromanganese; the total dose of thyroid extract was trifling. Her health was fair till January, 1932, when her doctor pronounced her a nervous wreck. In September, 1932, a diagnosis of thyrotoxicosis was made. In March, 1933, she had a severe crisis; this was controlled with iodine, and as authoritative opinion regards operation during a crisis as contraindicated she was sent home till it should pass over. Three weeks later she was returned to the nursing home as an acute emergency case with a running pulse of 180 , diarrhoea and vomiting, and in a state of. uncontrollable agitation. Her weight had fallen from a normal of $11 \mathrm{st} .10 \mathrm{lb}$. to under 7 st. The patient's restlessness was controlled by general anaesthesia (ether); heroin was administered hypodermically and Lugol's solution per rectum. In twenty-four hours she received 90 minims of the solution by mouth and rectum. Her pulse fell to 80 to 90 per minute. The Lugol's solution was discontinued and heroin was given daily. After five days the effect of the iodine ceased and she relapsed. She was then prepared with Lugol's solution for ten days, and on May 15, 1933, the right side and isthmus were operated on, the left side being done on June 5 . Convalescence after both operations was rapid, and by October, 1933, she had regained normal weight, health, and vigour, and has since remained well.

\section{CASE II}

Miss H. B., aged 22, was admitted on November 2, 1937, for typical acute primary thyrotoxicosis of a year's duration, with tiredness, nervousness, shortness of breath, palpitation, and sweating, but no loss of weight ; the pulse rate was often 160 per minute. She had had $x$-ray treatment from May to September and Lugol's iodine for the same period without benefit. The basal metabolic rate on November 5 was +73 per cent., and the blood pressure $168 / 70$. The thyroid gland was symmetrically enlarged and of the firm iodined type. The patient was kept under medical treatment, and the gland became softer and the pulse less rapid, but the latter rose very readily to 140 to 150 . Lugol's solution was begun on December 28, 7 minims thrice daily. On January 8, 1938, her pulse was still very excitable, and rose to 142 during the period of the doctor's visits. At 2 p.m. on January 8 she had a rectal saline containing 50 minims of Lugol's solution; a half-hourly chart showed a gradual and remarkable descent

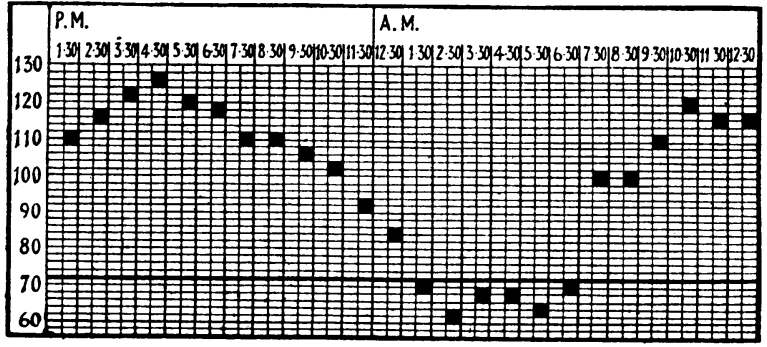

Fig. C.-Pulse chart showing the dramatic effect of 50 minims of Lugol's solution given in a rectal saline to a thyrotoxic patient (Case II)

of the pulse from 130 at 4 p.m. to 60 at 2 a.m., and it remained below 70 till 6.30 a.m. (see Fig. C). When I felt it the next day. at 2.30 p.m. it was 132. She was given another 50 minims of Lugol's solution per rectum at 2 p.m., and the pulse again fell steadily to 64 at $12.30 \mathrm{a} . \mathrm{m}$. The following day at 2.30 p.m. it was 120 . On the evening of the 10th the patient had 70 minims of Lugol's solution per rectum. On the 11 th, at 8 a.m., she had $\frac{1}{4}$ grain of morphine and $1 / 200$ grain of hyoscine; at 9 a.m. $\frac{1}{4}$ grain and $1 / 200$; and at 9.36 a little open ether and $1 / 6$ grain morphine. The neck was infiltrated with novocain ( $\frac{1}{2}$ per cent.), and bilateral subtotal thyroidectomy was performed without further anaesthesia, nine-tenths of the gland being removed. Before she left the theatre I told the patient that the complete operation had been performed; in spite of the heavy dosage of "twilight sleep" she smiled happily and said how relieved she felt; 30 minims of Lugol's solution were. given per rectum on return to the ward. Convalescence was rapid, and she was discharged ten days after operation, on January 21 , in excellent condition, with a pulse of 80 . The wound had been healed for several days.

These cases show: (1) the possibility of successful operation during an acute crisis if well controlled by iodine; (2) the large dosage of iodine that can be given-the second patient had 263 minims of Lugol's solution in seventy-two hours ( 200 per rectum, 63 by mouth); (3) the 
dramatic effect of a Lugol saline in an iodized patient; (4) the dosage of hyoscine and morphine that can be given in an acute case.

\section{Delayed Diagnosis as a Cause of Death}

The surgery of thyrotoxicosis is passing through a stage comparable to that of the long-neglected hernia, the big fibroid, and the late acute abdomen. The same pathetic fear of surgery which delayed treatment of these lesions twenty-five years ago is preventing early and safer treatment of thyrotoxicosis to-day. The same waiting for a fully developed picture is retarding early diagnosis. An incomplete picture is said to wear a mask. These masks, in particular the fibrillating heart, in proportion as the distinctive features of the disease become better known, are changed from masks to identification badges which suggest the diagnosis and lead to further investigation. Many a thyroid patient, having recovered from operation, says: "I feel in better health than I have enjoyed for many years"-sometimes ten or twenty years; but the diagnosis is recent, and these poor patients have suffered years of ill-health. Thyrotoxicosis presents a remarkable variety of clinical pictures. Its symptoms are manifested by disorder of the autonomic nervous system, and fall, apparently haphazard, with varied emphasis, on the organs under autonomic control. Taking the commoner signs and symptoms from the top of the head to the sole of the foot, the percentage incidence in cases coming under my care in this part of Yorkshire is roughly: nervousness or mental upset, 100 per cent. ; increased rapidity of the pulse or auricular fibrillation, 100 per cent. ; tremor, distinguishable from normal, 90 per cent.; easily produced fatigue, 80 per cent. ; loss of weight, 80 per cent. ; palpitation or thumping (or both), 75 per cent.; excessive perspiration, or dislike of heat, 70 per cent.; shortness of breath, 60 per cent. ; digestive symptoms, 50 per cent.; headache, 30 per cent. ; interference with the voice, 20 per cent. Eye-stare is common, exophthalmos is not so frequent, and swelling of the eyelids, swelling of the feet, anaemia, and anginal pain occur now and then. Where these symptoms are too few to render the condition obvious the disease is said to be masked. These masks are limited in number; let me mention the chief ones.

\section{The Thyrotoxic "Masks"}

1. The Cardiac Mask.-This is the commonest, a fact clearly brought out in the above statistics. These patients usually come with shortness of breath; some have a brief history, others date slight symptoms many years back. Hay (1936), in a charming paper on the thyrotoxic heart, pleads for the earlier diagnosis of those cases and for treatment at a period corresponding to that of the grumbling appendix. If anyone doubts the genuine difficulty which often exists in detecting thyrotoxicosis in those cardiac cases a single reading of Hay's paper will fully convince him ; and diagnosis is very important, as operative treatment is brilliantly successful.

2. The Mental Mask.-The mental cases come as melancholia, mental depression with suicidal tendencies, and nervous breakdown with mental symptoms. Dunhill (1937) emphasizes the need for a mental expert to establish the diagnosis.

3. The Abdominal Mask.-The presenting symptoms may consist of a very accurate simulation of gastric or duodenal ulcer; or of a long history of bilious attacks. The following case demonstrates the cure of abdominal symptoms by operation on a goitre.
CASE III

Mrs. C., aged 48, had had severe stomach trouble for five years (since 1931). The attacks lasted one to six weeks, and consisted of continuous epigastric pain relieved (only for a short time) by food. Intervals of freedom lasted two to three months. She had to lie up very often, and in 1933 was advised (after $x$-ray examination) to have an operation for duodenal ulcer. She was sent to me in February, 1936, for the above symptoms and for a right-sided adenoma of the thyroid. The adenoma was growing, causing dyspnoea on exertion, marked fatigue, especially during the last two years, sweating, tremor, and slight tachycardia. The removal of the adenoma (March 5, 1936) completely cured the dyspepsia. The patient writes as follows: "It is now twenty months since my operation; my neck is now normal, the scar almost unnoticeable, and my dyspepsia trouble a thing of the past. I take ordinary food, sleep well, and my weight is normal; in fact, I feel I have taken a new lease of life."

4. General Debility and Nervous Breakdown.-Cases which have lurked behind this diagnosis for many years enter on a new era of health when the disease is identified and treated.

5. The Absence of a Clinically Detectable Goitre.Careful examination will often find a goitre which is not at first obvious. Joll, speaking from his very large experience, declares that the thyroid is invariably enlarged in thyrotoxicosis. I believe personally that there are exceptions to this rule, as, for example, the following case.

\section{CASE IV}

Mrs. H., aged 49, had had typical symptoms of thyrotoxicosis of an aggravated type ; the basal metabolic rate, carefully and satisfactorily taken, was +54 per cent.; there was no goitre whatever (see Figs. 1 and 2 on Plate). At operation at least five-sixths of the total gland was taken away; the part removed weighed 7.81 grammes. The normal weight of the female thyroid gland exceeds 25 grammes. The patient made a dramatic improvement.

Hay (1936) states that thyrotoxicosis can exist without any clinically detectable enlargement of the thyroid gland. I believe the best rule is to assume that the thyroid need not be enlarged, but that the diagnosis must be clearly established before a case without enlargement of the gland is operated on for thyrotoxicosis.

\section{Surgery in Thyrotoxicosis}

Can the death rate be reduced by regarding thyrotoxicosis as a purely surgical disease? Nearly all writers are very guarded indeed in their answer to this question. All are agreed that operative treatment of a gland so valuable as the thyroid is to be regretted, and hope that medical research may find a better way. In the meantime operative results are such as to challenge every other method of treatment. There are no more brilliant results in the whole realm of medicine and surgery than the thyroid case after successful operation. But there can be a considerable mortality; and there can be many operative failures. All writers lay emphasis upon the fact that to obtain uniform success in this operation requires a degree of skill, judgment, gentleness, precision, and experience, together with a study of the individual patient and the winning of his or her confidence, much exceeding the care and skill needed for the average surgical operation. Don (1931), in a critical estimate of the late results of operation, states that there are comparatively few follow-up studies. In forty-two cases which he investigated in detail results were good in twenty-eight, there was improvement in nine, and little benefit in five. The statistics he quotes are on very similar lines. 


\section{Results of Operation for Thyrotoxicosis}

The brilliant results which often follow operation, and some of the published papers, may readily give the impression that nearly 100 per cent. cure is attainable. Dunhill (1934) expressly warns us that such is not the case. In order to judge my own results $I$ investigated the cases operated on by me for thyrotoxicosis in Bradford Royal Infirmary during the three years ending July 31 , 1937-that is, some months before this paper was written. During this period I performed 218 operations upon 190 patients. Scarcely any cases sent to me were rejected. All types were represented, and many elderly debilitated wrecks were included. Two patients died as a result of the operation, both from acute thyrotoxicosis; 188 out of the 190 left the hospital convalescing satisfactorily. All patients were prepared with Lugol's iodine, and operation time was determined sofiely by clinical judgment, independently of the basal metabolic rate or electrocardiogram, though these were often taken in the later cases. There were no deaths under anaesthesia. Morphine and hyoscine (in doses carefully adapted to the individual patient) with $\frac{1}{2}$ per cent. novocain, and occasionally some open ether at the beginning, constituted the anaesthetic. This anaesthesia compares very favourably with newer and more popular methods; it does not necessitate any special apparatus, and an anaesthetist was rarely needed. The operation is carried out quietly and deliberately, without haste ; after-sickness is not common, and chest complications are practically unknown. The patients were nursed in a ward of twenty-five beds, without a special nurse.

As there was no follow-up clinic I have been unable to trace all cases. One hundred and sixty-two replies were received to a questionary and many of the patients were interviewed. Two had died-one two months, the other two years, after leaving hospital-from causes not known. The other 160 replied without exception that they were improved by the operation. Only 107-that is, 67 per cent.-were fit for a full day's work, and, even of those, 18 per cent. had some minor complaint such as feeling tired at night, occasional dizziness, or rheumatism.

The main interest of this inquiry lay in finding out the reasons why the remaining fifty-three patients (33 per cent.) were not equal to a full day's work. Those patients fell into a series of groups: (1) the elderly and debilitated who never would do a full day's work again; (2) those who had never enjoyed good health and upon whose debilitated physique thyrotoxicosis had been engrafted, the cure of the thyroid condition restoring them to their original indifferent health; (3) those with associated diseases, such as arthritis and heart disease; (4) those who could not afford a proper convalescence and returned to a troubled domestic atmosphere, adverse economic circumstances, or even the nursing of sick relatives; (5) those in whom there had been a defect in the operative technique, such as leaving rather more thyroid gland than the individual required; (6) a miscellaneous group where the patient refused removal of the second side or retained obvious septic foci, or where not enough time had elapsed for complete recovery.

In private patients the results are much better than in hospital: the original physique is better, operation is performed earlier, and conditions for convalescence are much more favourable. Ample time should be allowed for convalescence, as not only has the patient to recover from the operation and the antecedent debility, but the remaining fragment of thyroid gland has to adjust itself to the needs of the body and the unknown cause of the thyroid malfunction has to subside. A follow-up clinic is very useful.

Two cases of exceptional interest may be recorded.

CASE V: LOCALIZED MYXOEDEMA

A sea pilot aged 43 suffered from typical thyrotoxicosis developing over two years, characterized by much loss of weight, palpitation, excessive perspiration, hoarseness, cough, occasional depression, tremor, and quick pulse. Subtotal bilateral thyroidectomy was performed. He made a rapid and perfect recovery in every respect except one. Four months before operation two thickened areas had appeared over the front of each shin-bone. These grew somewhat after operation for a few months, then remained steady, and a year and a half after operation grew slightly again. They constitute large patches, each about 7 inches by 7 inches, on the front of the tibia starting $1 \frac{1}{2}$ inches above the ankle, with a raised margin, slightly reddened surface, not tender, not pitting on pressure, and causing the patient no inconvenience whatever except from their weight and unsightliness (see Fig. 3 on Plate). This case was identified by Dr. J. T. Ingram, who published an article (1933) on circumscribed myxoedema associated with hyperthyroidism. This condition is referred to by Dunhill (1937), and he considers it to be mucinoid degeneration.

\section{CASE VI: JUVENILE PRECOCITY AFTER OPERATION}

A girl aged 9 years had suffered for a year from typical symptoms of Graves's disease with exophthalmos. Her pulse readily rose to 160 . She had failed to respond to nonoperative methods of treatment. Her condition being well controlled by iodine, she was cured by a two-stage operation in the summer of 1932. I had some misgivings about performing a subtotal thyroidectomy at the age of 9 for fear of interfering with her future development. On the contrary, at the age of 14 this girl might easily have been mistaken for a finished young lady 23 years old, her manner, habits, outlook on life, and physique being those of a modern young adult. Dunhill (1937) refers to juvenile precocity occurring after operation for thyrotoxicosis.

\section{Summary and Conclusions}

The central problem discussed is the high and increasing death rate from thyrotoxicosis. The 1,696 individual deaths occurring in England and Wales in 1936 are analysed. Allied problems such as the sphere of iodine in treatment, early diagnosis, and surgical results are discussed. The general conclusion is that the increase in the certified death rate is due not to a single cause but to several. There is an apparent increase owing to more accurate diagnosis, so that cases in which patients were previously certified as dying from heart disease and many other causes are now correctly elassified under the heading of thyrotoxicosis. There is a notable surgical mortality. Delay in surgical treatment until the patient is very ill is a contributory cause. The abuse of iodine as a medical treatment may play an important part. There may be an actual increase in the severity of the disease. These conclusions suggest that the certified deaths are more likely to increase than to diminish in the immediate future.

REFERENCES

Campbell, J. M. H. (1924-5). Quart. J. Med., 18, 191.

Don, C. S. D. (1931). British Medical Journal, 2, 287.

Dunhill, T. P. (1934). St. Bart's Hosp. J., 67, 184. (1937). British Medical Journal, 1, 515.

Fraser, F. R. (1936). Index of Treatment (Ed. R. Hutchison), 398, Bristol.

Hay, J. (1936). Lancet, 2, 1378.

Ingram, J. T. (1933). Brit. J. Derm. Syph., 45, 19.

Joll, C. A. (1932). Diseases of the Thyroid Gland, 486, London. Morley, J. (1936). British Medical Journal, 1, 828.

Wheeler, W. I. de Courcy (1934). Ibid., 2, 609. 
PETER MCEWAN : CLINICAL PROBLEMS OF THYROTOXICOSIS )

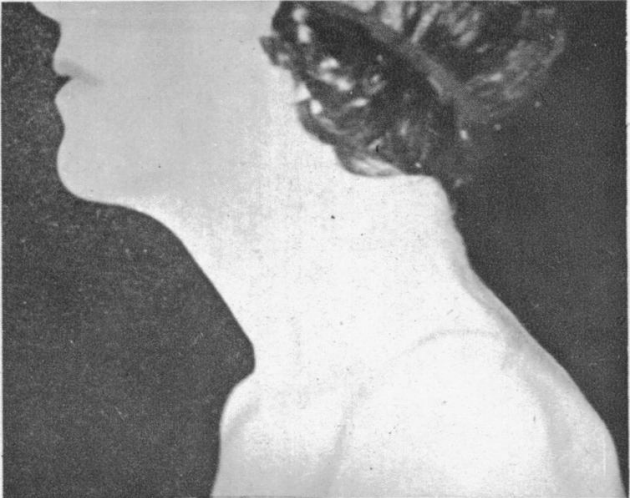

FIG. 1.

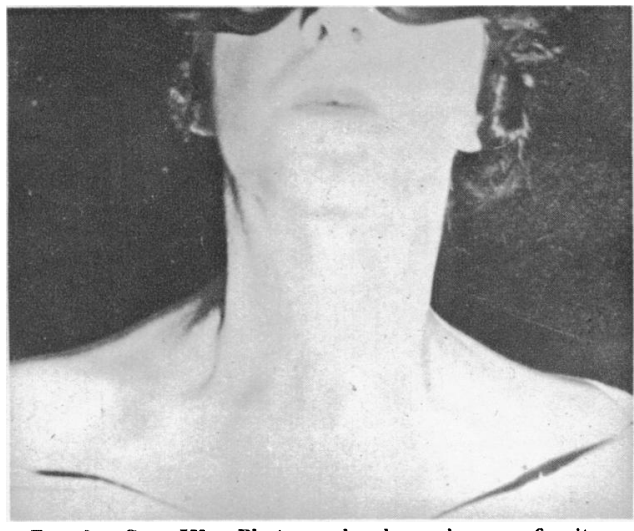

Fic. 2.-Case IV. Photographs show absence of goitre in a case of well-narked thyrotoxicosis (B.M.R. +54

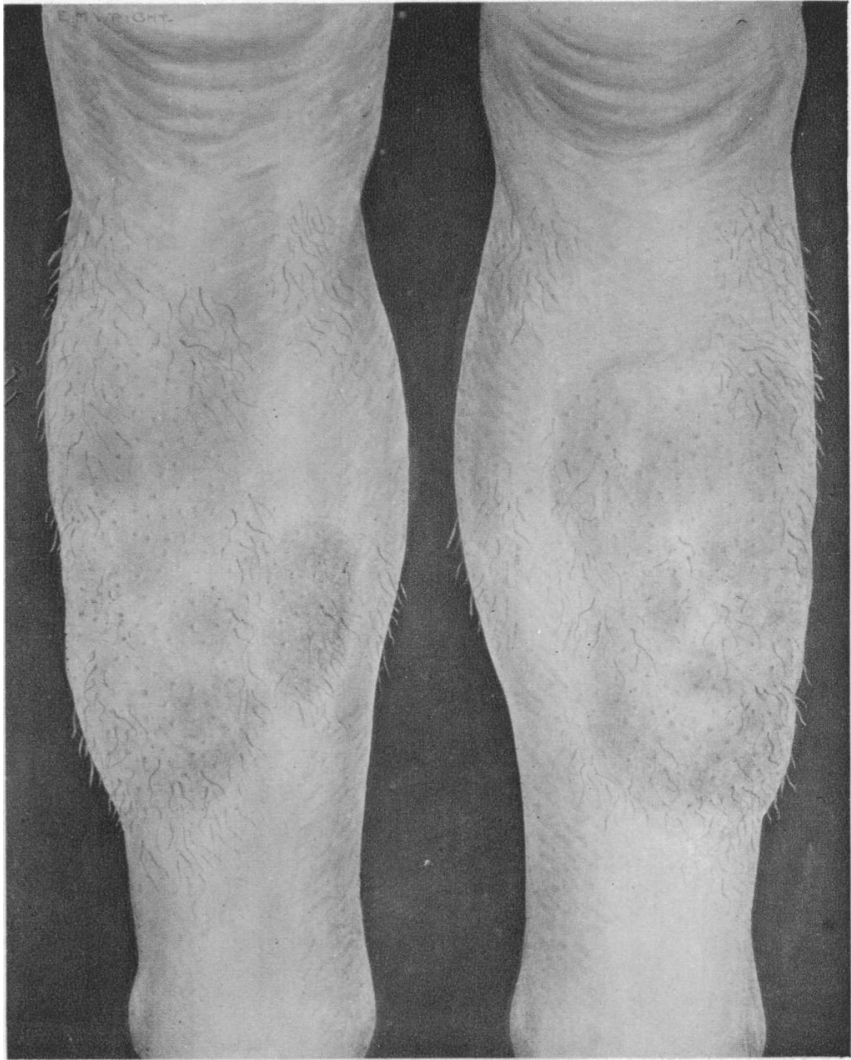

Fio. 3.-Case v. "Iocalized myxoedema" occurring before and increasing Blightly after an otherwise complete cure of thyrotoxicosis by subtotal per cent.).

R. G. COOKE : AN ANALYSIS OF 350 CASES OF ABORTION

\section{3}

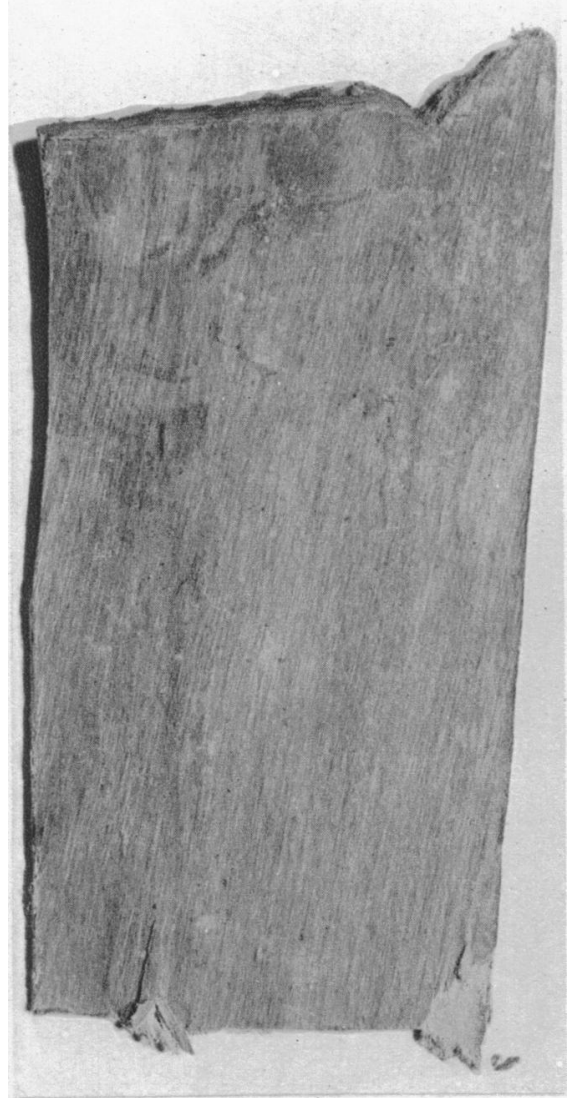

Fia. 1.-A piece of slippery elm bark.

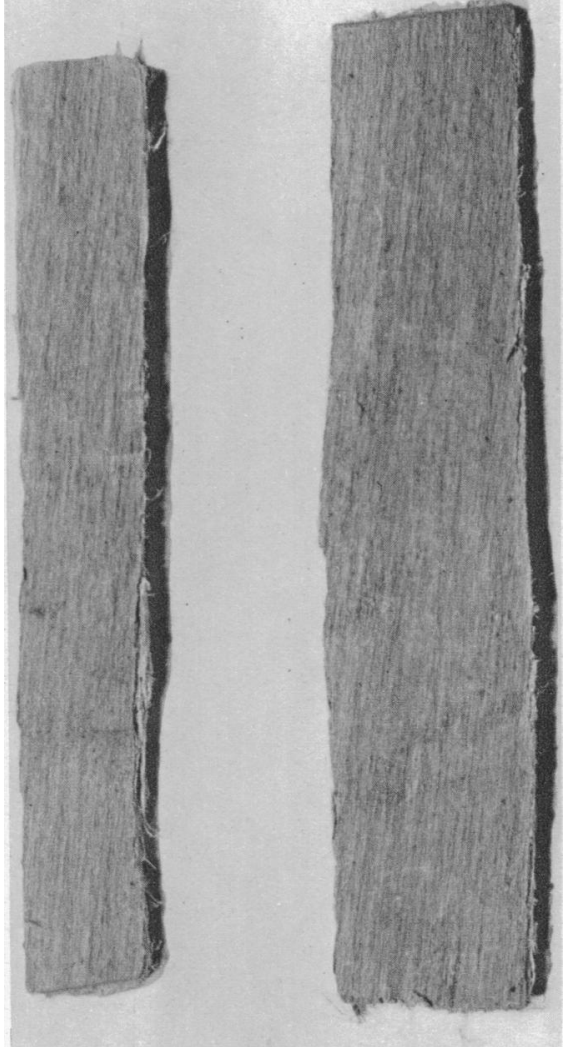

Fig. 2.- Showing increase in size of a small piece of bark on soaking in water.

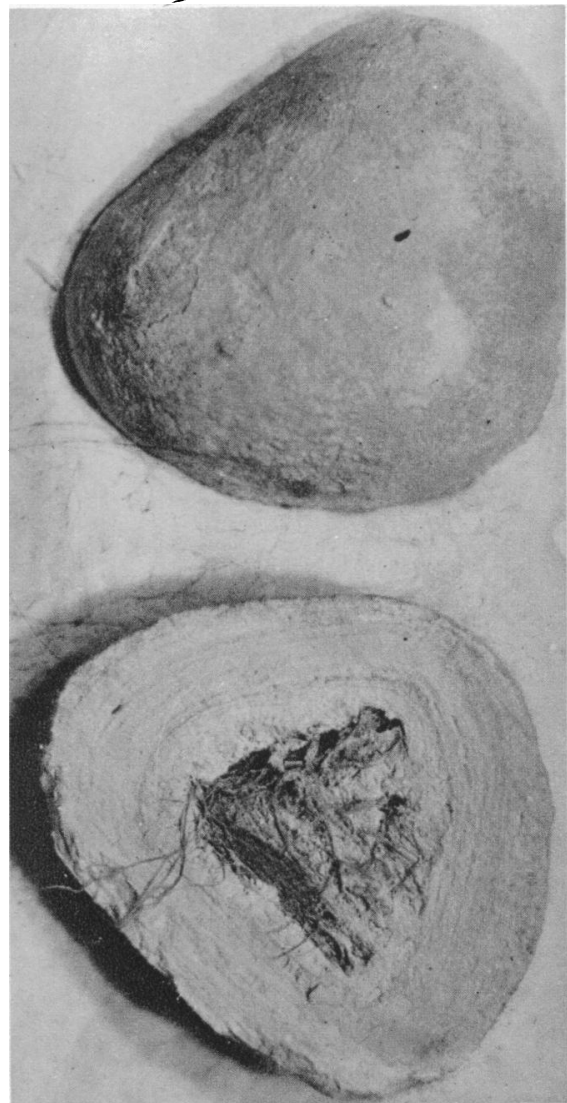

Fig. 3.-Stone from the bladder with nucleus of slippery elm. 